\title{
Space Charge in Polymers, Particularly Polyethylene
}

\author{
R. J. Fleming \\ Department of Physics \\ Monash University, Clayton, Victoria 3168 Australia \\ Received 7 October, 1998
}

\begin{abstract}
Electronic charge transport in insulating polymers is briefly discussed, particularly the measurement of charge carrier mobility. The more frequently used techniques of space charge profile measurement in dielectrics are then described, and data for polyethylene published during the last 5-6 years are reviewed.
\end{abstract}

\section{Introduction}

Although dielectric loss measurements on insulating polymers were reported as early as 1941 [1], relatively little fundamental research aimed at understanding charge transport and trapping in these materials appeared in the literature until the mid-1950s. By that time it had been established that their dc dark conductivities usually increase by several orders of magnitude under the influence of low level ionizing radiation $[2,3]$, and workers in the field then used the concepts of carrier excitation, trapping and recombination developed earlier for inorganic insulators to interpret their data. Our present day understanding of the effects of ionizing radiation on charge transport and trapping in dielectrics owes much to the sustained work of Gross and his colleagues over a period of at least 25 years [4-10].

A fairly satisfactory semi-quantitative model for charge injection, trapping and transport in polymers has gradually evolved [11,12]. In this model, electrons move through crystalline regions of the material with high mobilities (of order 1-10 $\mathrm{cm}^{2} \mathrm{~V}^{-1} \mathrm{~s}^{-1}$ ), occupying extended states originating in the covalent bonding between repeat units on the backbone of a single long chain molecule; this is intramolecular motion. Electron transport through the amorphous regions is achieved by hopping between localized states in which the electrons are immobilized for varying times; this involves both intra- and intermolecular motion, and is characterized by much lower mobilities $\left(10^{-11}-10^{-12} \mathrm{~cm}^{2} \mathrm{~V}^{-1}\right.$ $\mathrm{s}^{-1}$ ). (See however the discussion of field-dependent "mobilities" below). Electron transfer between localized states probably occurs mainly via tunnelling, pre- ceded by phonon-driven excitation of the electron to a state from which tunnelling is more likely.

This model is consistent with macroscopic measurements such as (a) time-dependence of the current flow following application and removal of a dc voltage, i.e. absorption and resorption current respectively, (b) field-dependence of the steady-state current, (c) temperature dependence of the current flow when the sample is heated in short circuit after voltage application at a higher temperature and cooling with the field still applied, i.e. thermally stimulated discharge current (TSDC) and the many possible variations thereof, and the influence of the choice of electrode material on charge injection and conductivity.

Two other sets of data are required in order to raise the level of our understanding of the electrical properties of polymer dielectrics to that of our understanding of the electrical properties of metals and semiconductors. They are (i) electronic drift mobility values, over a wide range of temperature and electric field, and (ii) the density, polarity and spatial distribution of space charge accumulating within polymer dielectric sheets subjected to dc fields at temperatures from room temperature upwards.

The latter is the main topic of this paper, and is discussed in sections III and IV. As a preliminary we consider electronic mobility briefly.

\section{Electronic mobility}

Electron/hole mobility data for polymers are sparse because of the difficulty of the measurements. In the conventional time-of-flight technique [13], heavy trapping 
frequently obliterates the knee or peak in the currenttime plot which is taken as marking the arrival of the leading edge of the injected carrier sheet at the distant electrode. Thus mobility values can usually be obtained in this way only for very thin samples. The situation is complicated by the fact that the measured mobilities usually increase with increasing applied field [14], whereas mobility as conventionally defined is fieldindependent.

Most of the reported mobility measurements on polymers using the time-of-flight technique are for polyethylene (PE). The earliest values reported for low density polyethylene (LDPE) fall into two groups, one around $10^{-4} \mathrm{~cm}^{2} \mathrm{~V}^{-1} \mathrm{~s}^{-1}$ at room temperature $[15,16]$, and the other in the range $10^{-10}$ to $10^{-11} \mathrm{~cm}^{2} \mathrm{~V}^{-1} \mathrm{~s}^{-1}$ at room temperature and at $80-95^{\circ} \mathrm{C}[17,18]$. The first group of authors appear to be reporting mobilities unaffected by trapping. Some remarkable data of this type obtained by Gross et al. [19] for electron-beam irradiated polytetrafluoroethylene (Teflon) samples should be mentioned; they observed a knee in the current-time plot as long as 10 s after the 1s long electron irradiation pulse which generated the excess carriers, and deduced a field-independent hole mobility of $2 \times 10^{-9} \mathrm{~cm}^{2} \mathrm{~V}^{-1}$ $\mathrm{s}^{-1}$ at room temperature.

A variation on the time-of-flight technique was introduced by Fischer and Rohl [20]. They observed maxima in current-time plots for oxidized LDPE samples at times around $10^{3} \mathrm{~s}$ after application of dc fields of order $100 \mathrm{kV} / \mathrm{cm}$. They interpreted these maxima as the transit times of charge carriers between the electrodes under a space-charge-limited-current (SCLC) regime. The calculated mobilities at $71^{\circ} \mathrm{C}$ were in the range $2-7 \times 10^{-11} \mathrm{~cm}^{2} \mathrm{~V}^{-1} \mathrm{~s}^{-1}$. Similar data for LDPE at $70^{\circ} \mathrm{C}$ under high pressure (15-50MPa) [21] suggest field- and pressure-dependent electronic charge carrier mobilities in the range $5 \times 10^{-11}$ to $7 \times 10^{-10} \mathrm{~cm}^{2} \mathrm{~V}^{-1}$ $\mathrm{s}^{-1}$. The temperature dependence of electron mobility in LDPE has also been reported [22] ; again an SCLC regime was assumed, and values of $4.2 \times 10^{-11}$ and $2.3 \times 10^{-10} \mathrm{~cm}^{2} \mathrm{~V}^{-1} \mathrm{~s}^{-1}$ were deduced at 50 and $70^{\circ} \mathrm{C}$ respectively, both for an applied field of $24 \mathrm{kV} / \mathrm{mm}$. A lower bound of $1.4 \times 10^{-10} \mathrm{~cm}^{2} \mathrm{~V}^{-1} \mathrm{~s}^{-1}$ for crosslinked polyethyene (XLPE), based on space charge profile measurements, has been suggested [23].

An alternative technique, ideally suited to the measurement of very low mobilities, uses the decay of charge on the surface of a dielectric, as a result of its transport into the bulk or its neutralization by other carriers mov- ing up from the bulk [24]. The surface charge is usually generated by bringing the dielectric surface into contact with a metal, or exposing it to a corona discharge. This technique would be expected to yield reliable data, yet very few workers seem to have adopted it $[25,26]$. It may be that the difficulty sometimes encountered in distinguishing between electronic and ionic carriers is regarded as too great a disadvantage. Mobility values obtained for PE using this method are $10^{-9} \mathrm{~cm}^{2} \mathrm{~V}^{-1}$ $\mathrm{s}^{-1}$ for electrons at $80^{\circ} \mathrm{C}$, and $2 \times 10^{-10} \mathrm{~cm}^{2} \mathrm{~V}^{-1} \mathrm{~s}^{-1}$ for unspecified carriers at room temperature [24].

\section{Space charge measurement}

\subsection{General}

In the context of dielectrics, the term "space charge" is usually taken to mean uncompensated real charge generated in the bulk of the sample as a result of (a) charge injection from the electrodes, driven by a $\mathrm{dc}$ field not less than approximately $10 \mathrm{kV} / \mathrm{mm}$, (b) field-assisted thermal ionization of impurities in the bulk of the dielectric, and (c) application of a mechanical/thermal stress, if the material is piezoelectric/pyroelectric. One must also remember that a bound (or apparent) volume charge density $-\nabla \cdot \underline{P}$, where $\underline{P}$ is the polarization vector, will be generated by partial alignment of permanent dipolar molecules distributed through the bulk [27]. Such polarization also generates a bound surface charge $\underline{P} \cdot \underline{a}_{n}$, where $\underline{a}_{n}$ is a unit vector normal to the dielectric surface, directed outwardly. Clearly there will be no volume bound charge unless the polarization is inhomogeneous, i.e. $-\nabla \cdot \underline{P} \neq 0$ Charge densities accumulating in polymeric dielectrics as a result of one or more of these processes are typically in the range 0.1 to $1 \mu \mathrm{c} / \mathrm{cm}^{3}$ [28].

It is of interest to note that space charge may accumulate in a block of dielectric even if none of the three charge generating processes listed above occurs $[29,30]$. Specifically, space charge with equilibrium density $\rho=\underline{J} \cdot \nabla(\epsilon / \sigma)$ will appear in the bulk, where $\underline{J}$ is the steady state volume current density, $\epsilon$ is the absolute permittivity of the dielectric $\left(=\epsilon_{r} \epsilon_{0}\right)$ and $\sigma$ is its conductivity. Clearly $\rho \neq 0$ provided a steady-state current is flowing and $\epsilon / \sigma$ is not constant. A significant dependence of $\sigma$ on temperature and electric field is to be expected in a polymeric insulator [29]; the corresponding variation in $\epsilon_{r}$ is expected to be much smaller [31]. Insertion of typical parameter values for a $250 \mathrm{kV}$ 
500MW XLPE-insulated cable yields space charge densities of order $10 \mathrm{nC} / \mathrm{cm}^{3}$ [30], about two orders of magnitude smaller than those commonly reported. Coelho et al. [31,32] arrive at a figure one order of magnitude larger, based on a slightly different choice of cable parameters, and point out that such densities are measurable using state-of-the-art equipment.

\subsection{Space charge measurement techniques}

The evolution of space charge measurement techniques has been described in detail by Lewiner [33], and those now in common use have been extensively documented very recently by Ahmed and Srinivas [34]. Consequently only the techniques most frequently used at the present time will be discussed here.

Today's successful non-destructive space charge measurement techniques are essentially adaptations and improvements of the technique introduced by Collins in the mid-1970s [35]. The common characteristic is a temporary, non-destructive displacment of the space charge in the bulk of the sample created by a travelling disturbance, such as a thermal or pressure wave, leading to a time-dependent change in the charge induced on the electrodes by the space charge (Fig.1).

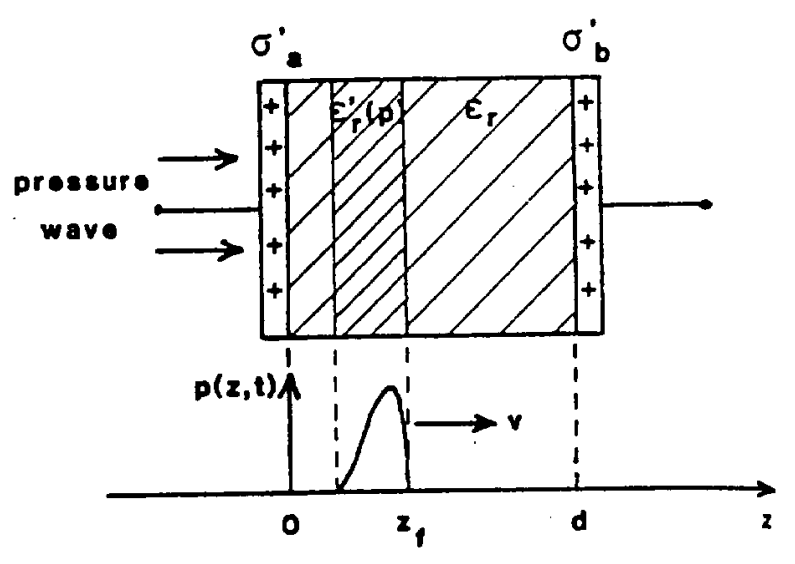

Figure 1. Principle of the thermal/acoustic wave techniques for measuring space charge profile. The travelling wave (speed v) temporarily displaces the charge in the bulk, and changes the relative permittivity of the dielectric from $\epsilon_{r}$ to $\epsilon_{r^{\prime}}$. The resulting changes in the charge induced on the electrode toward which the disturbance is travelling are analyzed to obtain the space charge profile in the bulk. From Ref. [33].

Compression or expansion of the sample will also contribute to the change in induced charge on the electrodes, through a change in relative permittivity. The change in electrode charge is analyzed to yield the space charge distribution. (It has been shown however that the thermal pulse technique, as originally implemented by Collins [35], yields only the first moment of the charge distribution and its first few Fourier coefficients, since small errors $(<1 \%)$ in the measured open-circuit voltage signal $V(t)$ can cause large errors in the deduced distribution [36]). A comprehensive account of the basic physics underlying the pressure wave techniques will be found in [37].

\subsubsection{Thermal techniques}

Two major developments of Collins' approach, also involving heating of the sample, are the laser-intensitymodulation-method (LIMM) [38] and the thermal step method [39]. In the former, both surfaces of a thin film sample are exposed to a sinusoidally-modulated laser beam (usually red) which is heavily absorbed by the electrodes. The resulting sinusoidal variation in the temperature of the electrodes generates periodic temperature fluctuations throughout the sample volume, which interact with the space charge to generate a pyroelectric current. This current is determined by the modulation frequency and the space charge distribution; measurements are taken at several frequencies. A deconvolution procedure is required to extract the distribution from the data. The best attainable spatial resolution is about $2 \mu \mathrm{m}$, but the resolution is of course much better near the sample surfaces than in the interior, because of the attenuation and dispersion of the heat waves in transit. (The corresponding degradation occurs in the other techniques described below). The maximum sample thickness is determined largely by the frequency range of the lock-in amplification equipment used; with commercially available equipment operating between $10 \mathrm{mHz}$ and $1 \mathrm{MHz}$, polymeric samples with thicknesses between $1 \mu \mathrm{m}$ and $2 \mathrm{~mm}$ can be investigated, assuming a (typical) thermal diffusivity value around $10^{-3} \mathrm{~cm}^{2} / \mathrm{s}$.

In the thermal step method [39], both electrodes are initially in contact with a heat sink at a temperature around $-10^{\circ} \mathrm{C}$. A heat source (typically at $20^{\circ} \mathrm{C}$ ) is then brought into contact with one electrode, and the temperature profile through the sample begins to evolve towards an equilibrium consistent with the new boundary conditions. The resulting thermal expansion of the sample causes a current to flow between the electrodes, and application of an appropriate deconvolution procedure using Fourier analysis allows extraction of the space charge distribution from the current flow data. This technique is particularly suited to thicker 
samples, say between 2 and $20 \mathrm{~mm}$, because there is essentially an unlimited amount of heat available and useful data can be collected until the temperature distribution across the sample has equilibrated. However the spatial resolution, about $150 \mu \mathrm{m}$, is much inferior to that of the LIMM methods. A recent paper [40] describes how deconvolution can be achieved using a matrix inversion technique, yieding much improved spatial resolution and requiring less computation time.

\subsubsection{Acoustic techniques}

A temporary displacement of space charge can also be achieved using a pressure pulse in the form of a longitudinal sound wave. Such a wave is generated, through conservation of momentum, when a small volume of a target attached to the sample is ablated following absorption of energy delivered in the form of a short laser pulse. Two laboratories developed this approach, naming it the pressure-wavepropagation (PWP) method [41] and the laser-inducepressure- pulse (LIPP) method [42]. Although these names are nowadays synonymous, implying the use of laser- generated pressure pulses, the earliest PWP results were obtained using pressure pulses generated by shock wave tubes [43]. The great advantage of the LIPP (or PWP) method is that, since the pressure pulses are short (typically 5ns), the space charge profile in a polymeric sample (speed of sound $\approx 2000 \mathrm{~m} / \mathrm{s}$ ) can be obtained without deconvolution, with a spatial resolution of at worst $10 \%$ of the sample thickness, provided the sample thickness is not less than approximately $100 \mu \mathrm{m}$.

Alternatively, a pressure pulse may be generated electro-acoustically by applying a short voltage pulse across the sample. The resulting electric field exerts a force on the whole space charge distribution, thereby generating acoustic pulses over the entire sample volume with pressure proportional to the local charge density [44]. Those pulses propagate through the sample towards both electrodes, and are detected by a grounded piezoelectric transducer attached to one of them. While deconvolution was initially required to extract the space charge distribution from the transducer output, even in thin samples, the use of thin transducers based on polyvinylidene fluoride has now largely eliminated the need for deconvolution. This method is commonly called the pulsed-electro-acoustic (PEA) or the electrically-stimulated-acoustic-wave (ESAW) method.

Assuming no instrumentation limitations, the spatial resolution of the acoustic techniques is, for practi- cal purposes, the product of the pressure pulse duration and the speed of sound in the sample. The pressure pulse duration in LIPP measurements depends on the laser pulse duration, and to some extent this can be chosen to suit the sample thickness, i.e. the thinner the sample the shorter should be the laser pulse. Considering a PE sample with aerosol graphite electrodes a few $\mu \mathrm{m}$ thick, a $1 \mathrm{~ns}$ laser pulse will generate a pressure pulse of approximately 5ns duration; taking the speed of sound as $2 \mathrm{~km} / \mathrm{sec}$ in polyethylene, we calculate a theoretical spatial resolution of $10 \mu \mathrm{m}$. In the PEA method the pressure pulse duration will equal the voltage pulse duration, but the latter is usually not less than $20 \mathrm{~ns}$ for the $3-4 \mathrm{kV}$ pulse heights customarily employed. Consequently a theoretical resolution of about $40 \mu \mathrm{m}$ is expected for polyethylene. However the thickness of the piezoelectric transducer must also be considered, since the practicable resolution improves with decreasing transducer thickness. A resolution of approximately $3 \mu \mathrm{m}$ has been claimed recently for a $100 \mu \mathrm{m}$ thick polyethyleneterephthalate sample [45], using a $4 \mu \mathrm{m}$ thick PVDF transducer, a 5ns long voltage pulse with $100-300 \mathrm{~V}$ amplitude, an impedance matching circuit to reduce degradation of the voltage pulse wave form by reflection, and FFT deconvolution of the output signal to compensate for the frequency characteristics of the transducer.

The minimum sample thickness for the acoustic techniques is around ten times the spatial resolution, and the maximum sample thickness is determined by attenuation and dispersion of the pressure pulse in transit. Correction for attenuation and dispersion of the pressure pulse in transit across the specimen should be made for polymeric samples more than approximately $100 \mu \mathrm{m}$ thick, but few authors do so. A suitable procedure has been outlined [46]. In a polyethylene sample, correction of LIPP and PEA data for attenuation and dispersion becomes inaccurate at thicknesses beyond 4$5 \mathrm{~mm}$. However, PEA measurements on samples more than $5 \mathrm{~mm}$ thick have been reported [47].

An interesting and very recent development of the PWP method yields a 3-dimensional mapping of the space charge profile [48]. A $400 \mathrm{~ns} 500 \mathrm{~V}$ voltage pulse applied to a piezoelectric device generates a pressure pulse which is focussed onto the upper surface (XY) of the sample by an acoustic lens. The diameter of the pressure pulse at the focus is about $0.8 \mathrm{~mm}$, so that the spatial resolution in the XY plane is approximately $1 \mathrm{~mm}^{2}$. A commercial stage moves the acoustic lens 
in the XY plane over an area of $20 \times 20 \mathrm{~mm}^{2}$. The resolution in the $\mathrm{z}$-direction is of course determined as described above. Data from a $0.5 \mathrm{~mm}$ thick polymethylmethacrylate sample, which had been exposed to an electron beam through a lead plate in which a slot in the form of the digit 7 had been cut, provide convincing evidence of the viability of this technique (Fig.2).

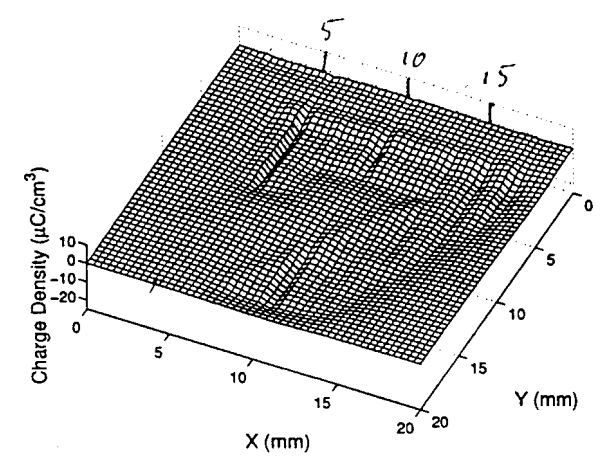

(a) At $Z=120 \mu \mathrm{m}$

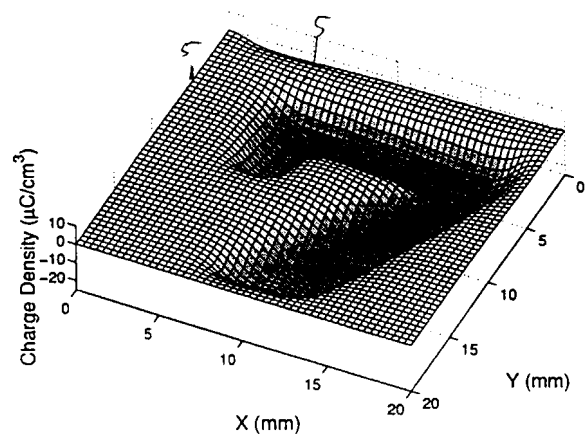

(c) At $Z=175 \mu \mathrm{m}$

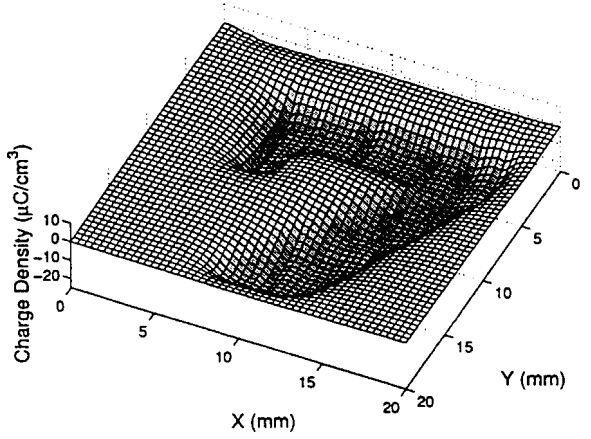

(b) At $Z=148 \mu \mathrm{m}$

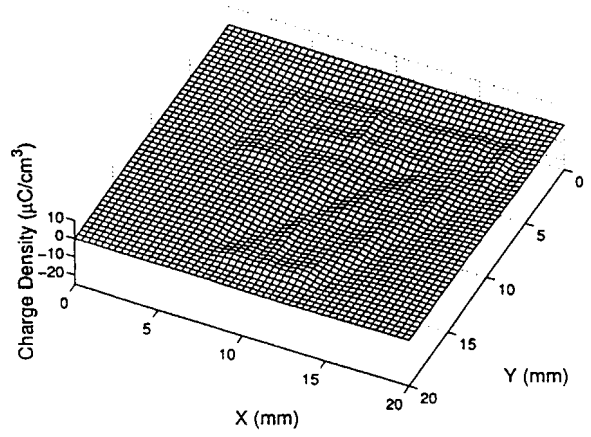

(d) At $Z=340 \mu \mathrm{m}$

Figure 2. Space charge profiles in the XY plane of a $500 \mu \mathrm{m}$ thick polymethylmethacrylate sample, which had been exposed to an electron beam $(200 \mathrm{keV})$ through a lead plate in which a slot in the form of the digit 7 had been cut. (a) at depth $120 \mu \mathrm{m}$ below the irradiated surface (Z-direction), (b) at depth $148 \mu \mathrm{m}$, (c) at depth $175 \mu \mathrm{m}$, (d) at depth $340 \mu \mathrm{m}$. The maximum trapped electron density was around $175 \mu \mathrm{m}$. From Ref. [48].

Of the techniques discussed above, LIPP and PEA are by far the most frequently used nowadays. The complementary nature of the LIMM and PWP techniques has been discussed recently [49].

\section{Space charge in polymers}

\subsection{General}

During the last fifteen years or so a vast body of experimental data on space charge accumulation in polymeric materials has been published. These data, or at least those for commercially important polymers such as polytetrafluoroethylene (PTFE), the copolymer fluorinated ethylene- propylene (FEP), polyimide (PI) and polypropylene (PP) have been reviewed recently [28]. $\mathrm{PE}$ was deliberately omitted from that review. Since (a) space charge in PE has not been reviewed recently, (b) the topic is of considerable importance to the power cable manufacturing industry, and (c) probably more space charge measurements have been made on PE than on any other polymer, measurements reported during the last 5-6 years are reviewed below. An excellent account of the various forms of PE, its morphology and the associated manufacturing techniques will be found in [50].

\subsection{PE}

It is convenient to discuss low density polyethylene (LDPE), high density polyethylene (HDPE) and crosslinked polyethylene (XLPE) separately.

\subsubsection{LDPE}

LDPE was chosen as the insulation in $225 \mathrm{kV}$ ac power distribution cables in 1969, and improvements in raw material purity and manufacturing processes since then have led to the present widespread use of crosslinked low density polyethylene (XLPE) as insulation 
in ac cables operating at $420 \mathrm{kV}$ and higher [51]. However, attempts over the last 25 years to use LDPE in high voltage dc cables have been largely unsuccessful, because the accumulation of space charge in the insulation distorts the electric field profile, causing the local field strength to exceed the breakdown value at particular points and so leading to cable failure.

\subsubsection{Role of low molecular mass species}

Lee et al (22( used the PEA method to investigate space charge accumulation, and the dependence of conductivity on applied field and sample thickness, in three types of sample. These were single layers with different number-average/weight-average molecular weight ratios, 2- and 3-layer laminates, and 2- and 3layer LDPE/(maleic anhydride-LDPE graft) laminates. The molecular weight ratios were varied by immersing the base LDPE in p-xylene at various temperatures between 53 and $73^{\circ} \mathrm{C}$. The semiconducting electrodes were vacuum-degassed for $100 \mathrm{hr}$ at $80^{\circ} \mathrm{C}$ before being attached with a hot iron. Heterocharge was observed in all the single layer samples, with decreasing density in samples from which increasing fractions of the "low molecular mass" species had been removed (Fig.3). The term "low molecular mass species" is not specifically defined, but appears to include very short $-\mathrm{CH}_{2^{-}}$chains, ketonic carbonyl groups, and various types of $\mathrm{C}=\mathrm{C}$ bonds. The authors concluded that the heterocharge originated mainly in the low molecular mass species. The 2- and 3-layer laminates also showed heterocharge profiles very similar to those of the single layer samples, prompting the deduction that there was little charge injection from the electrodes. The 2-layer LDPE/LDPE graft laminates developed negative charge at the internal interface when the LDPE was the cathode, the charge density decreasing as the low molecular mass species were progressively removed (Fig.4). The 3 -layer LDPE/LDPE graft/LDPE laminates developed negative charge at the internal interface nearer the cathode, and positive charge at the other interface; again the charge density decreased as the low molecular mass species were progressively removed. The steady state conduction current density and the effective carrier mobility also decreased when the concentration of low molecular mass species in the LDPE was reduced, suggesting that these species facilitate charge transport through the bulk. A dependence of the steady state current densities on (sample thickness) ${ }^{-3}$, and on (applied voltage $)^{n}$, where $2<n<3$ at all but the lowest voltages, strongly suggested an SCLC regime.

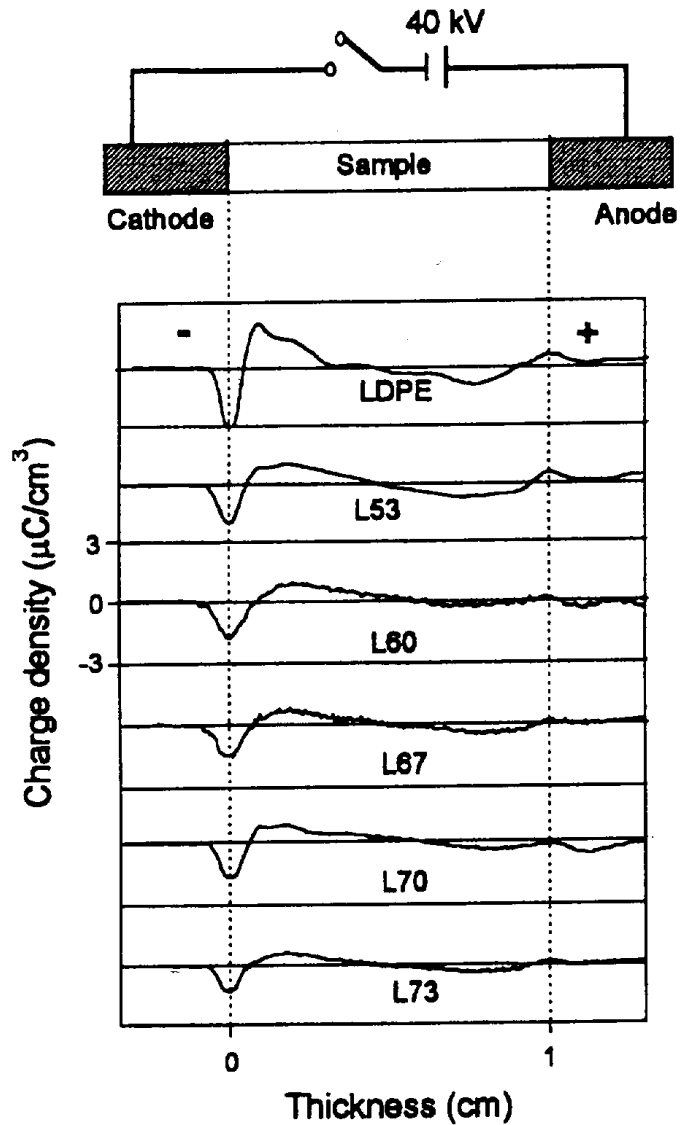

Figure 3. Space charge profiles in an LDPE sample and various residues, recorded in short circuit using the PEA method. The label L53 indicates the residue after lowmolecular-mass species had been partially extracted using $\mathrm{p}$-xylene at $53^{\circ} \mathrm{C}$. The traces show the charge in the bulk (mainly heterocharge) and the charge induced on the electrodes by the bulk charge. From Ref. [22].

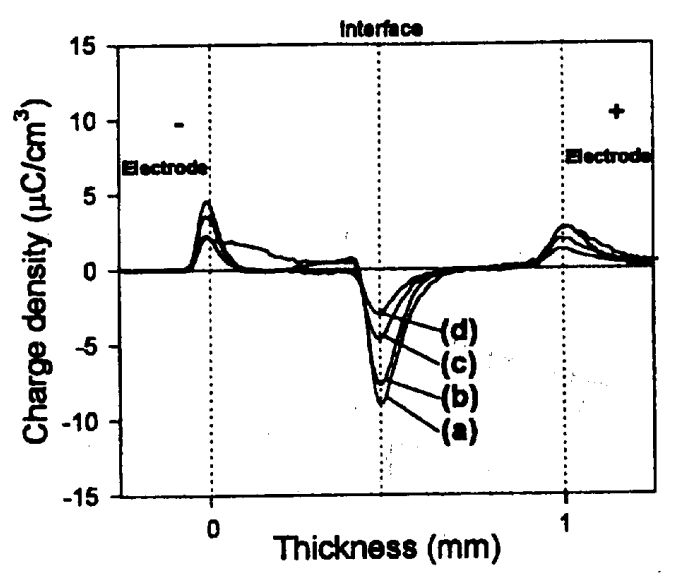

Figure 4. Space charge profiles in double laminate layers based on LDPE, residue and maleic anhydride- LDPE graft, recorded in short circuit using the PEA method. (a) LDPE cathode / graft anode, (b) R53 cathode /graft anode, (c) R60 cathode / graft anode, (d) R70 cathode / graft anode. R53 indicates the residue after low-molecular-mass species had been partially extracted using p-xylene at $53^{\circ} \mathrm{C}$. From Ref. [22]. 


\subsubsection{Influence of chemical modification}

The effects of grafting acrylic acid and n-butyl acrylate, and blending with copolymers of ethylene and nbutyl acrylate, have been reported [52]. The base material was additive-free, and the grafting reactions were initiated using dicumyl peroxide. The samples were typically $0.7 \mathrm{~mm}$ thick, excluding the $0.2 \mathrm{~mm}$ semicon electrodes fabricated from ethylene-vinyl-acetate and containing carbon black and antioxidants. The electrodes were vacuum-degassed for $100 \mathrm{hr}$ at $80^{\circ} \mathrm{C}$ before being attached to the samples. The base material showed heterocharge close to the electrodes. The density of the heterocharge decreased with increasing graft ratio of acrylic acid, and homocharge developed at graft ratios around $0.135 \%$ wt. However the density of heterocharge in the n-butyl-acrylate grafts exceeded that in the base material at all graft ratios (maximum 0.120 $\% \mathrm{wt}$ ). It was suggested that, in the acrylic acid grafts, the heterocharge decreases because the concentration of homocharge trapped at carbonyl groups increases. An anomalous result was observed in the LDPE/n-butylacrylate blends, namely that heterocharge increased in the blends up to $6 \%$ wt of the ethylene/n-butyl acrylate copolymers, although the copolymers themselves developed homocharge.

The thermal step technique has been used to study the effect of adding $5 \%$ wt of $\mathrm{BaTiO}_{3}$ [53]. The $\mathrm{BaTiO}_{3}$ particle size was $<7 \mu \mathrm{m}$, and the samples were approximately $1.9 \mathrm{~mm}$ thick. They were polarized for $72 \mathrm{hr}$ at $50^{\circ} \mathrm{C}$ at a field strength around $25 \mathrm{kV} / \mathrm{mm}$, and were immersed in paraffin oil during polarization in order to avoid flashover. The maximum space charge density $\left(0.4 \mu \mathrm{C} / \mathrm{cm}^{3}\right)$ in the $\mathrm{BaTiO}_{3}$-doped samples with vacuum-evaporated gold electrodes was only about $11 \%$ of the corresponding maximum in undoped samples with the same electrodes, and $27 \%$ of that in undoped samples with aluminium electrodes. The undoped samples showed dramatic alternation in space charge polarity across their thickness. Since previous work had shown that $\mathrm{BaTiO}_{3}$ greatly increases the conductivity of the LDPE, it was suggested that the increased conductivity leads to a much decreased space charge density. More specifically, since $\mathrm{BaTiO}_{3}$ is strongly polar, it will affect the LDPE morphology and reduce the extent of charge trapping.

\subsubsection{Influence of $\gamma$-irradiation}

Chen et al [54] used the LIPP technique to obtain some interesting data on space charge formation in $\gamma$ irradiated LDPE plaques, $350 \mu \mathrm{m}$ thick with sputtered gold electrodes. The unirradiated samples developed negative space charge adjacent to the anode, with density around $0.5 \mathrm{C} / \mathrm{m}^{3}$, after a dc field of $60 \mathrm{kV} / \mathrm{mm}$ had been applied for $6 \mathrm{hr}$. This was attributed to the migration of short charged LDPE chains. Samples irradiated in the absence of an applied field did not develop space charge; in the presence of a field the evolution of the profile was complex, depending on the field strength, the time for which it was applied and the absorbed dose. The profile decayed little with time when the samples, irradiated with the field applied, were shortcircuited. The authors attributed the evolving profiles to structural changes in the material with increasing dose, especially radiation-induced oxidation. They presented IR spectra showing a detectable concentration of $\mathrm{C}=\mathrm{O}$ groups after a $50 \mathrm{kGy}$ dose, but concluded that $\mathrm{C}=\mathrm{O}$ dipoles did not contribute to the space charge profile.

\subsubsection{Influence of pumping and heating}

Henriksen et al. [55] investigated $1.8 \mathrm{~mm}$ thick samples with $0.1 \mathrm{~mm}$ thick semicon electrodes. They conditioned them in short-circuit at $80^{\circ} \mathrm{C}$ for $48 \mathrm{hr}$ at rotary pump pressure, and then followed the development of the space charge profiles when dc fields of $20 \mathrm{kV} / \mathrm{mm}$ were applied at room temperature. Comparing the results with those for unconditioned samples, they found that the space charge was dominated by homocharge in the conditioned samples, and by heterocharge in the unconditioned samples. Conditioning tended to reduce the space charge density. The space charge profiles varied little when the samples (conditioned and unconditioned) were short-circuited, suggesting that electron transport through the bulk occurred through fieldassisted thermal hopping between localized trapping sites.

\subsubsection{Influence of electrodes}

A study of the dependence of the steady state dc conduction current density on temperature, applied field and sample thickness [56] led to the conclusion that the conductivity is influenced by the composition of the electrodes. The electrodes compared were silicone oil, sputtered aluminium and semiconductive XLPE containing carbon black. LDPE was mixed with Santonox R antioxidant (0.4 parts of antioxidant per hundred parts of LDPE), and XLPE was obtained by mixing dicumylperoxide and Santonox $\mathrm{R}$ antioxidant with LDPE (2 parts peroxide and 0.4 parts antioxidant per 100 parts polymer), and cross-linking under pressure at $180^{\circ} \mathrm{C}$ for 20 mins. The degree of crosslinking was $86 \%$. Measurements were made in the temperature range $25-100^{\circ} \mathrm{C}$, at fields between 1 and 60 $\mathrm{kV} / \mathrm{mm}$. The equilibrium current densities increased 
in the electrode order sputtered aluminium, semiconductive XLPE and silicone oil, while the conductivity activation energies increased in the opposite order. Activation energy as a function of applied field increased slightly with increasing field for sputtered aluminium and semiconductive XLPE, but decreased markedly for silicone oil. The slopes of log-log plots of current density against applied field increased from $\sim 1.0$ to $\sim 2.0$ around $10 \mathrm{kV} / \mathrm{mm}$, for both sputtered aluminium and semiconductive XLPE, prompting the authors to suggest ohmic conduction at low fields and a space-chargelimited-current (SCLC) regime at higher fields. (However, the current densities at higher fields were roughly two orders of magnitude larger for the semiconductive electrodes than for the sputtered aluminium electrodes; equal densities would be expected in samples of the same bulk material under SCLC conditions). In the case of the silicone oil contacts, the corresponding slopes were 2.13 below $10 \mathrm{kV} / \mathrm{mm}, 1.30$ between 10 and $30 \mathrm{kV} / \mathrm{mm}$, and 1.86 above $30 \mathrm{kV} / \mathrm{mm}$. No explanation of the latter observation was offered.

\subsubsection{HDPE}

Very little work on high density polyethylene (HDPE) has been reported, although one might expect a comparison between it, LDPE and XLPE to prove informative. Toureille and Vella [57] found significant charge densities in $2 \mathrm{~mm}$ thick planar samples as prepared, i.e. before voltage had been applied. The samples were compression moulded from extruded tapes of polyethylene base resins, in order to avoid the granular faces which abound in compressed pellet samples and which could complicate the space charge behaviour by acting as electron traps. (The authors do not state specifically that their samples were HDPE, but quoted crystalline fractions around $80 \%$ and densities around $960 \mathrm{~kg} / \mathrm{m}^{3}$ strongly suggest that they were). Four types of sample were prepared, with molecular weights (not precisely defined) of 48000, 59000, 71000 and 100000 $\mathrm{g} /$ mole, and with vacuum- evaporated aluminium electrodes. It was found that the higher the molecular weight, the greater the space charge density before application of voltage. If a sample was cooled symmetrically, i.e. at the same rate on both sides, positive charge appeared close to the electrodes and negative charge in the middle. One sample was cooled asymmetrically after moulding, and the resulting space charge profile compared with that in a symmetrically cooled sample. The latter showed a space charge density in the bulk adjacent to one of the electrodes approximately three times larger than that adjacent to the other electrode. The corresponding ratio in the asymmetrically cooled sample was around 12 , with the larger density adjacent to the more rapidly cooled face. A microscopic inspection of the samples showed smaller spherulites in the more rapidly cooled sample, demonstrating the influence of morphology on space charge accumulation. The authors chose to apply voltage across $1 \mathrm{~mm}$ thick samples (presumably of the same HDPE) with semiconductor electrodes, rather than the samples described above. Prior to voltage application, the space charge profiles in these thinner samples were similar to those in the other samples. Fields between 90 and $130 \mathrm{kV} / \mathrm{mm}$ were applied at $50-60^{\circ} \mathrm{C}$ for several hours, with the samples immersed in a liquid paraffin bath in order to avoid flashover. The profiles tended to retain the same shape as before poling, but the space charge densities increased. The results were interpreted as consistent with electron injection (presumably from the cathode) and an electrical conductivity gradient in the bulk following moulding, the conductivity being lower in the centre than at the edges.

\subsubsection{XLPE}

\subsubsection{Comparison of different cross-linking methods}

LIPP space charge profiles in XLPE cross- linked by the long-established dicumyl peroxide method, and by the more recent vinyl silane grafting method [50], have been compared [23]. Planar samples $0.5 \mathrm{~mm}$ thick were cut from power distribution cables, and self-fusing semiconducting polymeric tape was attached to both surfaces of each sample to form electrodes. DC fields up to $10 \mathrm{kV} / \mathrm{mm}$ were applied at temperatures in the range $20-90^{\circ} \mathrm{C}$. In both sample types nearly all the space charge accumulated within $100 \mu \mathrm{m}$ of the electrodes, and the densities were very similar. However, heterocharge was favoured by the samples cross-linked using dicumyl peroxide, and homocharge by the others, independent of the polarity of the applied voltage.

\subsubsection{Effects of reversing applied voltage po- larity}

In the work just discussed [23], both types of sample showed a near-perfect inversion of the equilibrium space charge profiles (concentrated near the electrodes) when the applied field polarity was reversed (Fig.5). This striking result was interpreted as indicating that electron transfer between the electrodes and the XLPE, in either direction, involved the same narrow window of donor and acceptor states in the XLPE, centred on the Fermi level, i.e. as envisaged in the Lewis model for charge transfer across interfaces [58]. 


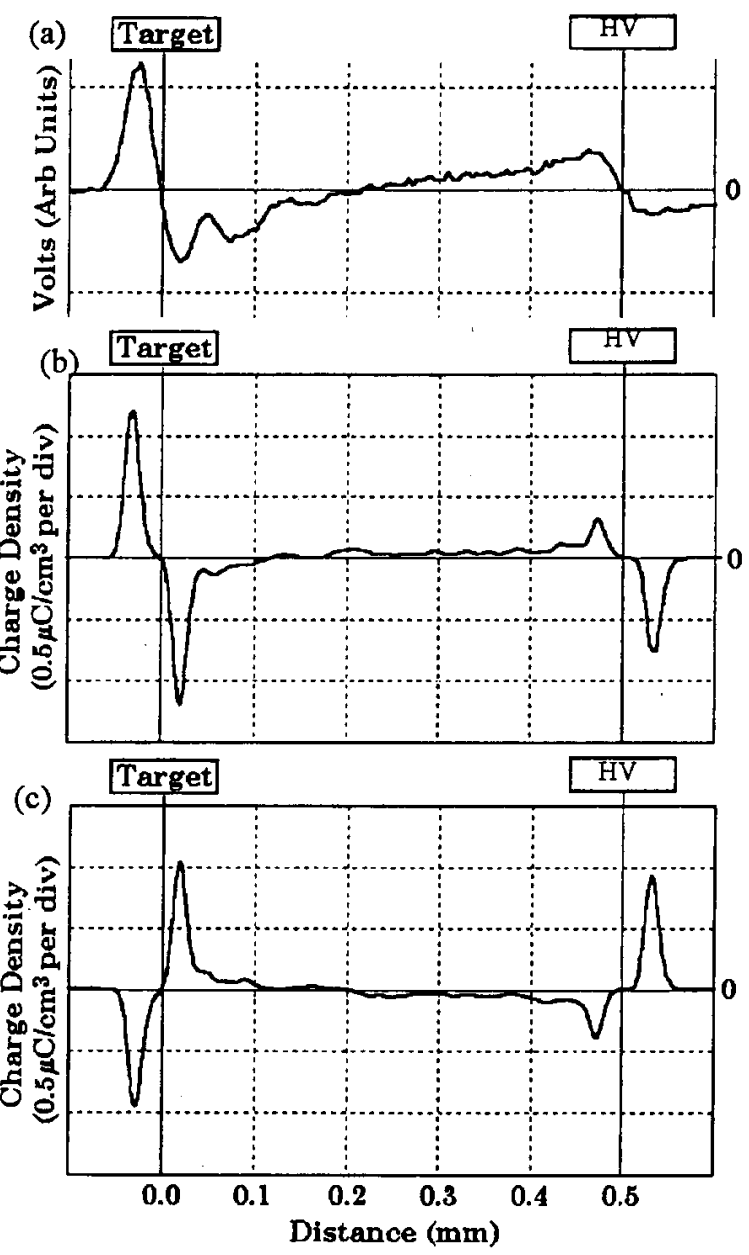

Figure 5. Space charge profiles for a planar XLPE sample, recorded in short circuit using the LIPP method. (a) after poling at $10 \mathrm{kV} / \mathrm{mm}$ with the target electrode as the anode (b) trace (a) after approximate correction for the finite width, dispersion and attenuation of the pressure pulse (c) corrected trace after poling at $10 \mathrm{kV} / \mathrm{mm}$ with the target electrode as the cathode. From Ref. [23].

Li and Takada [59] made measurements at room temperature on $2.5 \mathrm{~mm}$ thick XLPE sheets, with vacuum-evaporated aluminium electrodes. As-received samples contained $0.37 \mathrm{wt} \%$ and $0.82 \mathrm{wt} \%$ of acetophenone and cumyl alcohol respectively, while for samples which had been de-gassed for 4 days at $80^{\circ} \mathrm{C}$ under reduced pressure, the corresponding figures were 0.02 and $0.08 \mathrm{wt} \%$ respectively. Initially $-80 \mathrm{kV}$ was applied for $48 \mathrm{hr}$ (pre-load) across all samples. This was followed, for de-gassed samples, by $+80 \mathrm{kV}$ for $24 \mathrm{hr}$, $80 \mathrm{kV}$ for $24 \mathrm{hr},+60 \mathrm{kV}$ for $24 \mathrm{hr},-60 \mathrm{kV}$ for $24 \mathrm{hr}$ and similarly for $40 \mathrm{kV}$. As-received samples were subjected to the same voltage-time pattern, except that the voltages were 80,40 and $20 \mathrm{kV}$. Homocharge was dominant in the de-gassed samples, and heterocharge in the as-received samples. Homocharge was attributed to electronic injection/extraction at the electrodes, and heterocharge to ionization and transport of cross-linking byproducts. It was found that, on reversing the polarity of the applied voltage, charge of the opposite sign began to appear close to the electrodes within a few minutes, but complete disappearance of the original charge took several hours. The higher the applied voltage, the shorter the time to disappearance. It is difficult to gauge from the data presented how precisely the equilibrium charge profiles were inverted when the applied voltage was reversed, but the statement that "an interesting point is that the space charge distributions have rotary symmetry characteristics under $+80 \mathrm{kV}$ and $-80 \mathrm{kV}$ load" suggests fairly accurate inversion. However, assuming that the charge in the bulk was real charge, it is difficult to envisage a mechanism by which the net charge in any given small volume of the sample in equilibrium would be precisely reversed when the polarity of the applied voltage was reversed. The authors also commented that charges were readily tranported through the bulk and across the interfaces.

Some of the Li and Takada data [59] have been analyzed by Alison and Hill [60]. They carried out a computer simulation of charge transport in a planar sample with metallic electrodes, and adjusted trapping and recombination parameters to obtain the best fit to the experimental space charge profiles. They concentrated on the charge distribution adjacent to the electrode nearer to the piezoelectric transducer, since reflection of the pressure pulse from the other electrode made it difficult to obtain adequate accuracy in that region. They concluded that electron and hole injection and recombination influence the space charge patterns significantly. More specifically, injected homocharge recombines with trapped heterocharge (injected during application of the opposite voltage polarity) or occupies empty traps immediately adjacent to the injecting electrode, until all such traps are filled. Thereafter, filling of traps further away from the electrode occurs until the field is reduced sufficiently to suppress injection. Alison and Hill [60] do not comment specifically on the inversion of the profile following reversal of the applied voltage. However, perusal of some of the experimental space charge profiles, which they presented in conventional graphical format rather than the colour-coded pictorial format of Li and Takada [59], suggests that the equilibrium profiles under opposite applied voltage polarities were almost mirror images of each other.

Wang et al [61] used the PEA method to study space charge accumulation in lengths of freshly cured cylindrical power cable with $3.5 \mathrm{~mm}$ thick XLPE insulation. The two semicon layers were $1 \mathrm{~mm}$ thick, and the outer layer was exposed and used as the grounded electrode. $+40 \mathrm{kV}$ dc was applied for $2 \mathrm{hr}$, followed by 
$-40 \mathrm{kV}$ for $2 \mathrm{hr}$, at room temperature. The equilibrium space charge profiles, measured with the field applied, are shown in Fig.6. It will be seen that the profiles are almost mirror images of each other in the horizontal axis. The authors noted this inversion, but did not offer any explanation. In work on cable samples [62] using the LIPP technique, a similar reversal of profile on reversing the polarity of the applied voltage was observed. The profiles shown in Fig.7 (a) and (b) were recorded with the sample in short-circuit. The authors interpreted the reversal as evidence that the space charge originated mainly in inhomogeneous polarization in the sample bulk, due to an inhomogeneous spatial distribution of permanent dipoles. In other words, the space charge was bound charge. Assuming an individual dipole moment of 2 Debye, they estimated that a dipole concentration of at least eight dipoles per hundred $-\mathrm{CH}_{2^{-}}$groups would be required in some parts of the amorphous volume of the sample. This figure is consistent with a much earlier estimate based on a study of the piezoelectric effect in extruded polyethylene cable insulation [63].

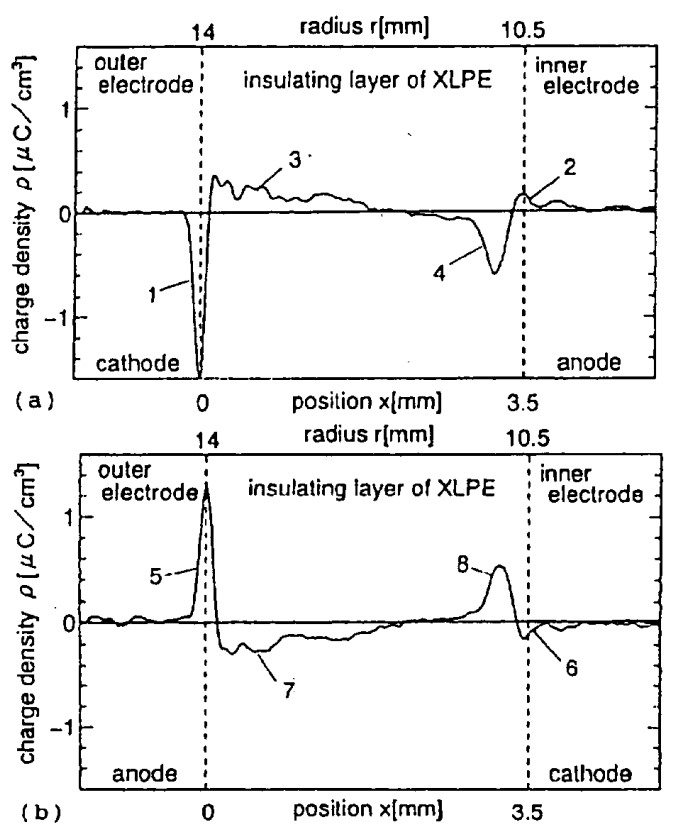

Figure 6. Radial space charge profiles in the XLPE insulation of a power cable, measured with voltage applied using the PEA method. (a) after $+40 \mathrm{kV}$ had been applied for $2 \mathrm{hr}$ - 1: negative surface charge induced on cathode, 2 : positive surface charge induced on anode, 3 : positive space charge accumulating in XLPE, 4: negative space charge accumulating in XLPE. (b) after $-40 \mathrm{kV}$ had been applied for $2 \mathrm{hr}$ - 5: positive surface charge induced on anode, 6 : negative surface charge induced on cathode, 7 : negative space charge accumulating in XLPE, 8: positive space charge accumulating in XLPE. From Ref [61].
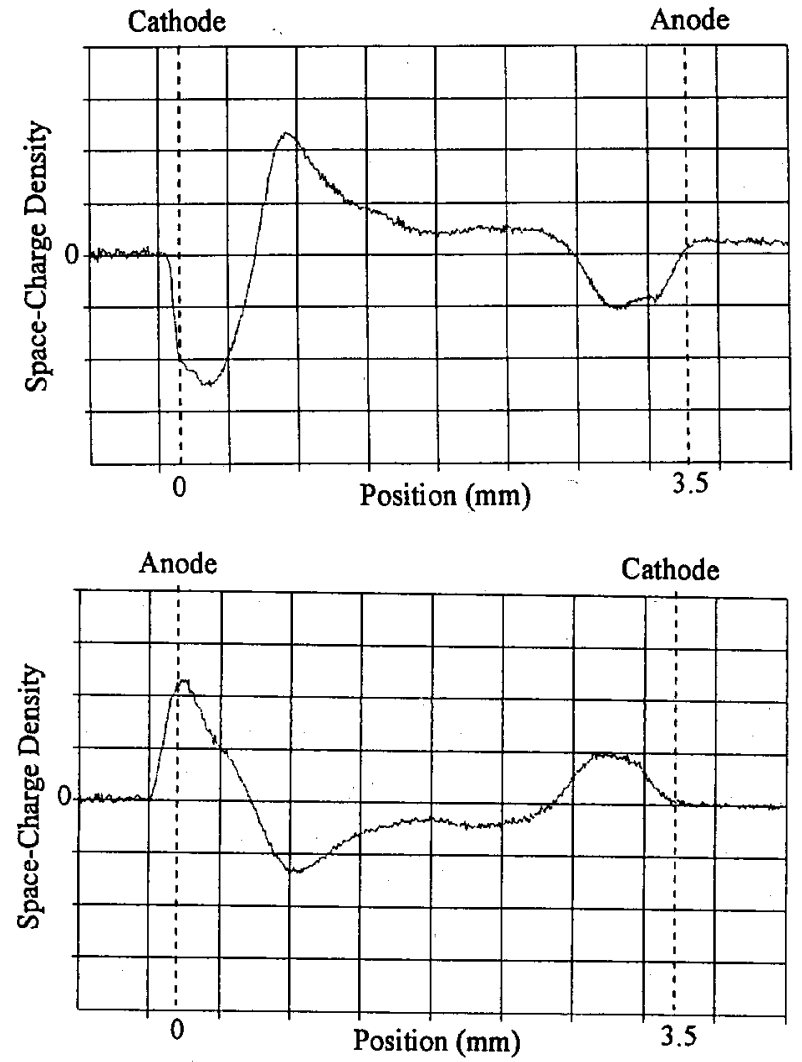

Figure 7. Radial space charge profiles in the XLPE insulation of a length of power cable, measured in short circuit using the LIPP method. The sample had been held at $82^{\circ} \mathrm{C}$ for $2 \mathrm{hr}$ at atmospheric pressure. (a) after $+54 \mathrm{kV}$ had been applied for $24 \mathrm{hr}$ (b) after $-54 \mathrm{kV}$ had been applied for $80 \mathrm{hr}$. Vertical scale (a) and (b) $0.14 \mu \mathrm{C} / \mathrm{cm}^{3}$ per division. From Ref. [62].

\subsubsection{Influence of pumping and heating}

Wang et al [61] found that previously accumulated space charge disappeared when the sample was held in short-circuit at temperatures in the range $25-80^{\circ} \mathrm{C}$ for $2 \mathrm{hr}$ in an air oven. However the charge re-appeared when the voltage was re-applied. On the other hand, holding the samples in short-circuit at $80^{\circ} \mathrm{C}$ and at pressures around $1.3 \mathrm{~Pa}$ for 10 days also removed any preexisting space charge, and prevented its re-appearance for at least $2 \mathrm{hr}$ when the voltage was re-applied at room temperature. This result was attributed to removal of volatile impurities and modification of the crystallineamorphous interfaces.

Lim et al [62] reported that pre-existing charge was removed when the sample was conditioned in short- circuit for $2 \mathrm{hr}$ at $82^{\circ} \mathrm{C}$ and atmospheric pressure, but, when voltage was applied, charge accumulated at a much faster rate than that observed before conditioning. Following conditioning in short-circuit for 10 days at $82^{\circ} \mathrm{C}$ and $0.1 \mathrm{~Pa}$, no space charge was detected until voltage had been applied for about $40 \mathrm{hr}$ after conditioning, and its density increased very slowly. Interestingly, 
if the sample was then conditioned for $2 \mathrm{hr}$ at $82^{\circ} \mathrm{C}$ and atmospheric pressure, the charge re-appeared at much the same rate as after conditioning at $82^{\circ} \mathrm{C}$ and atmospheric pressure. Elaborating on their model of bound space charge associated with a spatially inhomogeneous distribution of molecular dipoles, the authors suggested that the dipoles were formed in the amorphous regions of the samples by the combined effect of oxygen, water vapour and increased temperature, water vapour acting as a catalyst for a process equivalent to non-permanent oxidation of XLPE. The bound charge profile would be determined largely by the distribution of large volume voids, since the dipoles would be bulky. The dipoles would be destroyed by the combined effects of heating and pumping, probably through removal of oxygen.

Sanden [64] used the PEA method to investigate the effects of conditioning samples in an air-ventilated oven at $90^{\circ} \mathrm{C}$ for $72 \mathrm{hr}$. A twin-screw extruder was used to produce tape from cable quality XLPE granules. The tapes were then pressure moulded into cup-shaped samples, the planar bases being $1 \mathrm{~mm}$ thick with Rogowskiprofile edges. The electrodes were $0.5 \mathrm{~mm}$ thick, made from semiconducting cable screen material and containing the same crosslinking agent (dicumylperoxide) and antioxidant (Santonox R) as the XLPE. The electrodes were crosslinked to the XLPE during the pressure moulding. Space charge profiles for unconditioned and conditioned samples, subjected to dc fields in the range $20-70 \mathrm{kV} / \mathrm{mm}$ at $40^{\circ} \mathrm{C}$ for various times, were compared. The main conclusions were that (a) heterocharge formation originating in bulk processes was dominant in unconditioned samples, (b) homocharge injection from the electrodes was dominant in the conditioned samples at fields up to $40 \mathrm{kV} / \mathrm{mm}$, but additional heterocharge slowly accumulated near the cathode at higher fields, and (c) the space charge densities in the conditioned samples tended to saturate after the voltage had been applied for about 3 months. The additional heterocharge in (b) was attributed to electron extraction from low molecular weight polyethylene (presumably at the anode) and drift of the resulting positive ions towards the cathode.

\subsubsection{Influence of impurities}

The influence of additives and cross-linking byproducts on space charge formation in XLPE has been investigated by Suh et al [65]. They produced XLPE sheets from LDPE containing Santonox $\mathrm{R}$ antioxidant, and attached ethylene-vinylacetate copolymer electrodes loaded with carbon black, wax and antioxidant. Measurements were made at room temperature on four types of sample, as follows:

(1) Type 1 , as described immediately above.
(2) Type 2, obtained by holding Type 1 material at $80^{\circ} \mathrm{C}$ for $100 \mathrm{hr}$ at reduced pressure in order to remove cross-linking byproducts such as acetophenone, cumyl alcohol and $\alpha$-methylstyrene. These samples were considered to consist of a crosslinked XLPE volume, a non-cross-linked LDPE volume and antioxidant additive.

(3) Type 3 , obtained by subjecting Type 2 material to chloroform extraction for $48 \mathrm{hr}$ under ambient conditions, in order to remove the antioxidant. These samples were therefore considered to consist only of cross-linked XLPE and non-cross-linked LDPE.

(4) Type 4, obtained by immersing Type 3 material in boiling xylene for $48 \mathrm{hr}$ in order to remove the noncross-linked LDPE. The degree of cross-linking was $86 \%$.

The main conclusions were that (a) homocharge tends to accumulate in "pure" XLPE, and heterocharge in LDPE, (b) Santonox R prevents the formation of heterocharge in both XLPE and LDPE, and (c) crosslinking byproducts encourage heterocharge formation in XLPE. It was suggested that, since the cross-linking byproducts are believed to be low molecular weight molecules, they may readily acquire a charge and migrate to the appropriate electrode under the applied field. However, no explanation was offered for heterocharge formation in LDPE.

\subsubsection{Influence of electrodes}

In an attempt to explain the mechanism underlying the reversal of discharge currents, which has been reported by several authors in a range of polyethylenes (see references in [66]), Malec et al [66] measured discharge currents and space charge profiles in $1.5 \mathrm{~mm}$ thick samples with $200 \mu \mathrm{m}$ thick "carbon charged polyethylene" electrodes. They were short-circuited and dried in a vacuum oven for $48 \mathrm{hr}$, at temperatures up to $80^{\circ} \mathrm{C}$, before measurements were commenced. Polarizing fields in the range $13-33 \mathrm{kV} / \mathrm{mm}$ were applied for $1 \mathrm{hr}$, over the temperature range $30-70^{\circ} \mathrm{C}$ and the pressure range 0.1-30 MPa. Space charge measurements were made using the PWP (presumably LIPP) method, with the sample in short-circuit. Predominantly homocharge accumulation was observed. Computer simulation of the discharge current was carried out, starting from the measured space charge density profiles, and various assumptions about the electrode characteristics, e.g. fully- or partially-blocking, were tested. A range of charge carrier mobilities values was also investigated. The resulting calculated discharge currents were then compared with their measured counterparts. The calculated discharge currents 
did not reverse direction unless the electrodes were partially blocking, and the times at which reversal occurred placed fairly strict limits on the charge carrier mobilities (in the range $10^{-11}$ to $10^{-9} \mathrm{~cm}^{2} \mathrm{~V}^{-1} \mathrm{~s}^{-1}$ ). No mechanism which would render the electrodes partially blocking was suggested. The calculated mobilities were found to increase with increasing temperature, pressure and applied field.

A study of the dependence of the $\mathrm{dc}$ conduction current density on applied field, temperature and sample thickness, for fresh and de-gassed semiconductive XLPE electrodes, also led to the conclusion that the conductivity is influenced by the composition of the electrodes [56]. The samples were prepared by mixing dicumylperoxide and Santonox $\mathrm{R}$ antioxidant with LDPE ( 2 parts peroxide and 0.4 parts antioxidant per 100 parts LDPE), and cross-linking under pressure at $180^{\circ} \mathrm{C}$ for 20 mins. The degree of cross-linking was $86 \%$, and the sample thickness varied between 30 and $100 \mu \mathrm{m}$. The electrodes were of the same XLPE, with the addition of carbon black. Measurements were made in the temperature range $25-100^{\circ} \mathrm{C}$, at fields between 1 and $60 \mathrm{kV} / \mathrm{mm}$, and the current density measured 40min after application of the field was taken as the steady state value, since it varied little thereafter. Some samples were vacuum de-gassed in order to remove residual byproducts of the cross-linking reaction such as acetophenone, cumyl alcohol and $\alpha$ - methylstyrene. Loglog plots of steady-state current density J against electric field E, for samples in which one or both of the XLPE and the semiconductive electrodes had not been degassed, could be divided into three regions, labelled I, II and III in order of increasing field strength (Fig.8). In region I the slopes of the three combinations ranged between 1.7 and 2.0, suggesting an SCLC conduction regime. In region II the slopes varied from 0.4 to 1.4 , while in region III a much narrower range (2.2 to 2.3 ) was observed. A study of the dependence of $J$ on sample thickness d showed $J \propto d^{-n}$, with $n=3$ when neither electrodes nor XLPE had been degassed, and $n=2$ when one of the two had been de-gassed. It was concluded that the SCLC regime dominated the conduction in these samples, and that de-gassing probably introduced traps.

This study was extended by comparing the steadystate current densities in samples which had (i) been boiled in xylene in order to remove uncrosslinked LDPE, antioxidant and cross-linking residues, or (ii) chloroform-extracted to remove only antioxidant and cross-linking residues. The semiconductive XLPE electrodes were always vacuum de-gassed. In both types of sample $J$ increased steadily with increasing $\mathrm{E}$, with the slopes of log-log plots showing significant increases at field strengths around $5 \mathrm{kV} / \mathrm{mm}$. These slopes were in the range 2.6 to 3.5 , for temperatures between 50 and $100^{\circ} \mathrm{C}$. An investigation of the dependence of $J$ on sample thickness again showed $J \propto d^{-n}$, with $n$ in the range 2 to 3 , for both types of sample. The authors concluded that the conduction was probably dominated by the SCLC mechanism, with a range of trap depths. They also suggested that the reductions in the slopes of the $\log$ J v $\log$ E plots observed for untreated XLPE samples were due to the influence of low molecular weight species including cross-linking residues and byproducts.

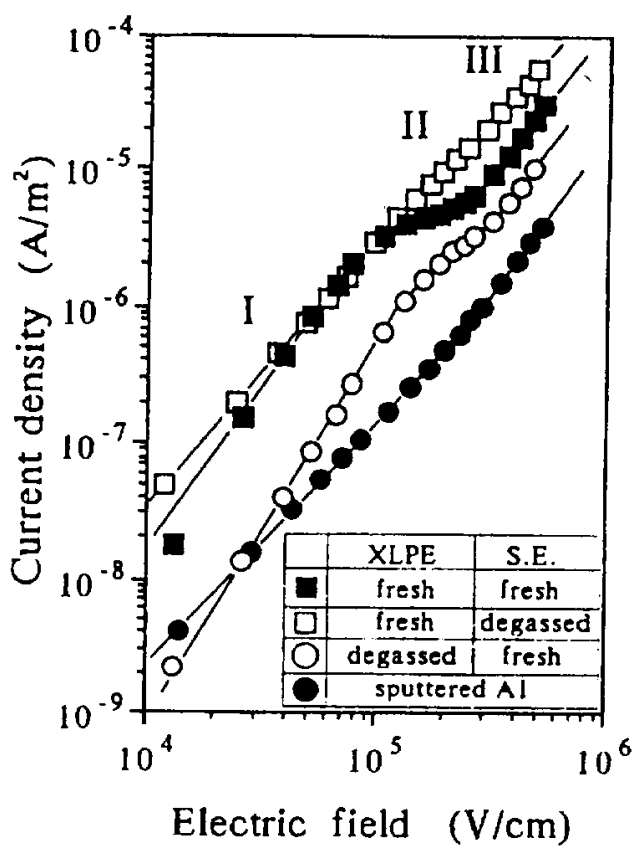

Figure 8. Current density versus applied field characteristics for XLPE samples with semiconductive electrodes at $90^{\circ} \mathrm{C}$. The inset specifies the state of the XLPE and the semiconductive electrodes, i.e. vacuum degassed or fresh (not vacuum degassed). From Ref. [56].

\subsubsection{Formation and transport of charge pack-} ets

High dc fields $(>70 \mathrm{kV} / \mathrm{mm})$ applied to XLPE cable samples have been reported to generate "packets" of positive charge which move through the sample [67]. The insulation thickness was $3 \mathrm{~mm}$, the inner and outer semiconducting shields were made from a copolymer of ethylene and vinylacetate loaded with carbon black, and the PEA space charge measurement technique was used. At lower field strengths heterocharges accumulated close to both electrodes at room temperature. When the central conductor was maintained at $60^{\circ} \mathrm{C}$ the packets were generated more frequently, and moved at speeds approximately ten times faster than at room temperature. These speeds are not specifically stated, 
but values of order $10^{-4} \mathrm{~cm} / \mathrm{sec}$ may be deduced from the mobility values assumed in charge transport simulation calculations included in the paper. It is difficult to extract accurate figures from the quasi-3D charge profiles, but the packets appear to be up to $1 \mathrm{~mm}$ wide with peak charge densities as high as $5 \mu \mathrm{C} / \mathrm{cm}^{3}$. These charge densities decreased in successive packets. Charge packet generation and transport were also observed in $2 \mathrm{~mm}$ thick XLPE and LDPE sheets with aluminium/semiconducting rubber electrodes. Space charge profiles in untreated sheets were compared with those in (a) sheets which had been dried for 5 days at $80^{\circ} \mathrm{C}$ and pressures less than 1 Torr, (b) sheets which had been immersed in acetophenone (a byproduct of dicumyl peroxide cross-linking) at $25^{\circ} \mathrm{C}$ for 1 day, and (c) sheets treated as in (b) and then held at $150^{\circ} \mathrm{C}$ for 1hr. The authors suggested that the likely mechanism of charge packet generation at high applied fields was ionization of impurities such as antioxidants following solvation in acetophenone.

\section{Conclusions}

The influence of conditioning procedures on the accumulation of space charge in polymers, and the dependence of the space charge density on the strength, polarity and time of application of the field, have been extensively investigated. There appears to be general agreement that vacuum de-gassing of samples and electrodes favours the formation of homocharge via charge injection from the electrodes, while impurities such as cross-linking residues and byproducts lead to greater heterocharge densities. However, the chemical identities of the impurities involved in heterocharge formation are rarely determined, and quantitative data such as charge carrier mobilities, trapping and recombination cross- sections, and the field-dependence of the injection rates at the electrodes, are infrequently extracted. Part of the reason for this is that samples are often inadequately characterized, chemically and physically. In the case of commercial material, e.g. power cable insulation, this is understandable. However, more carefully designed experimental sequences attempting to isolate a single experimental variable, e.g. a comparison of space charge profiles in samples of the same polymer but with different electrode materials, would allow more detailed conclusions to be drawn with confidence. Another important point is that space charge data are rarely collected at temperatures other than room temperature. LIPP measurements on heated samples are generally not any more difficult at elevated temperatures than at room temperature, and the use of lithium niobate as a piezoelectric detector, with a stable response up to at least $120^{\circ} \mathrm{C}$, should permit PEA measurements over a wide temperature range. Computer simulation of charge injection, transport and trapping is now readily achieved, and should be carried out in parallel with laboratory measurements. As always, the information which can be extracted from a single experimental technique, even one as powerful as LIPP or PEA, should be confirmed as far as possible with other forms of experimental data, e.g. thermally stimulated conductivity and discharge.

\section{Acknowledgments}

I wish to thank Professors Guilherme Leal Ferreira, Roberto Faria and Reimund Gerhard-Multhaupt for their kind invitation to contribute to this special issue in honour of Professor Bernhard Gross. I first met Bernhard in Miami in October 1972, at what was in effect the 2nd International Symposium on Electrets, although it went under another name at the time. I got to know him much better during the latter half of 1978, when we were both working as consultants at the then Bell Telephone Laboratories, Murray Hill, New Jersey.

Most of this paper was written while I was a guest Professor in the Department of Electric Power Engineering of the Technical University of Denmark. I wish to thank my hosts there for their unfailing hospitality, and the Tranes Foundation for financial support.

\section{References}

1 R.M. Fuoss, J. Amer. Chem. Soc. 63, 369 (1941).

2 J.F. Fowler and F.T. Farmer, Nature, 175, 590 (1955).

3 J.F. Fowler, Proc. Roy. Soc. London, A236, 464 (1956).

4 B. Gross, J. Appl. Phys. 36, 1635 (1965).

5 B. Gross and M.M. Perlman, J. Appl. Phys. 43, 853 (1972).

6 B. Gross, G.M. Sessler and J.E. West, J. Appl. Phys. 45, 2841 (1974).

7 L. Nunes de Oliveira and B. Gross, J. Appl. Phys. 46, 3132 (1975).

8 B. Gross, Radiation-Induced Charge Storage and Polarization Effects, Ch.4 in Electrets, (Topics in Applied Physics, 33) ed. G.M. Sessler, Springer-Verlag, Berlin, 1980.

9 R. Gregorio Filho, B. Gross and R.M. Faria, IEEE Trans.Elec.Insul. EI-21, 431 (1986).

10 R. Hessel and B. Gross, IEEE Trans. Elec. Insul. EI-27, 831 (1992).

11 L.A. Dissado and J.C. Fothergill, Electrical Degradation and Breakdown in Polymers, Peter Peregrinus Ltd. London, 1992, Ch. 2. 
12 D.K. Das-Gupta, IEEE Trans. Diel. Elec. Insul. 4, 149 (1997).

13 W.E. Spear, J. Non-Cryst. Solids, 1, 197 (1969).

14 (a) B.G. Bagley, Solid State Comms. 8, 345 (1970); (b) R. Nath and M.M. Perlman, J. Appl. Phys. 65, 4854 (1989).

15 D.K. Das-Gupta and T. Noon, J. Phys. D: Appl. Phys. 8, $1333(1975)$.

16 T. Tanaka and J.H. Calderwood, J. Phys. D: Appl. Phys. 7, 1295 (1974).

17 H.J. Wintle, J. Appl. Phys. 41, 4004 (1970).

18 E.H. Martin and J. Hirsch, J.Non-Cryst. Solids, 4, 133 (1970).

19 B. Gross, G.M. Sessler, H.von Seggern and J.E. West, Appl. Phys. Lett. 34, 555 (1979).

20 P. Fischer and P. Rohl, Progr. Colloid \& Polymer Sci. 62, 149 (1977).

21 D. Malec, V.H. Truong, R. Essolbi and T.G. Hoang, IEEE Trans. Diel. Elec. Insul. 5, 301 (1998).

22 S.H. Lee, J-K Park, C.R. Lee and K.S. Suh, IEEE Trans. Diel. Elec. Insul. 4, 425 (1997).

23 K.R. Bambery and R.J. Fleming, IEEE Trans. Diel. Elec. Insul. 5, 103 (1998).

24 D.K. Davies, (a) Institute of Physics (UK) Conf. Ser. No. 4, Static Electrification, 1967, p.29; (b) J. Phys. D: Appl. Phys. 5, 162 (1972).

25 T.J. Sonnonstine and M.M. Perlman, J. Appl. Phys. 46, 3975 (1975).

26 M.M. Perlman, T.J. Sonnonstine and J.A. St. Pierre, J. Appl. Phys. 47, 5016 (1976).

27 M.N.O. Sadiku, Elements of Electromagnetics, Oxford University Press, New York, 2nd Edition, 1995, p.195.

28 G.M. Sessler, IEEE Trans. Diel. Elec. Insul. 4, 614 (1997).

29 I.W. McAllister, G.C. Crichton and A. Pedersen, Conference Record 1994 IEEE Inter. Symp. Elec. Insul. p.212.

30 I.W. McAllister, G.C. Crichton and A. Pedersen, Conference Record 1996 IEEE Inter. Symp. Elec. Insul. p.661.

31 R. Coelho, B. Aladenize and F. Guillaumond, IEEE Trans. Diel. Elec. Insul. 4, 477 (1997).

32 B. Aladenize, R. Coelho, F. Guillaumond and P. Mirebeau, J. Electrostatics, 39(4), 235 (1997).

33 J. Lewiner, IEEE Trans.Elec.Insul. EI-21, 351 (1986).

34 N.H. Ahmed and N.N. Srinivas, IEEE Trans. Diel. Elec. Insul. 4, 644 (1997).

35 R.E. Collins, (a) Appl Phys Letters, 26, 675 (1975) (b) J. Appl. Phys. 48, 4804 (1976).

36 H. von Seggern, Appl. Phys. Letters, 33, 134 (1978).

37 R. Gerhard-Multhaupt, (a) Phys. Rev. B, 27, 2494 (1983) (b) Ferroelectrics, 75, 385 (1987).
38 (a) S.B. Lang and D.K. Das-Gupta, J. Appl. Phys. 59, 2151 (1986) (b) S.B. Lang, Ferroelectrics, 118, 343 (1991).

39 A. Cherifi, M. Abou Dakka and A. Toureille, IEEE Trans. Elec. Insul. EI-27, 1152 (1992).

40 M. Abou Dakka, S.S. Bamji and A.T. Bulinski, IEEE Trans.Diel.Elec.Insul. 4, 314 (1997).

41 C. Alquie, G. Dreyfus and J. Lewiner, Phys. Rev. Letters, 47, 1483 (1981).

42 G.M. Sessler, J.E. West and G. Gerhard, Phys. Rev. Letters, 48, 563 (1982).

43 P. Laurenceau, G. Dreyfus and J. Lewiner, Phys. Rev. Letters, 38, 46 (1977).

44 (a) Y. Li, M. Yasuda and T. Takada, IEEE Trans. Diel. Elec. Insul. 1, 188 (1994) (b) P. Morshuis and M. Jeroense, IEEE Elec. Insul. Magazine, 13(3), 26 (1997).

45 T. Maeno and K. Fukunaga, IEEE Trans. Diel. Elec. Insul. 3, 754 (1996).

46 T. Ditchi, C. Alquie and J. Lewiner, J. Acoust. Soc. Am. 94, 3061 (1993).

47 J.B. Bernstein and C.M. Cooke, IEEE Trans. Elec. Insul. EI-26, 1080 (1991).

48 X. Qin, K. Suzuki, M. Sazaki, Y. Tanaka and T. Takada, Proc.6th Int.Conf. on Conduction and Breakdown in Solid Dielectrics, IEEE Dielectrics and Electrical Insulation Society, Vasteras, Sweden, June 1998, p.13.

49 C. Boue, C. Alquie and D. Fournier, Ferroelectrics, 193, 175 (1997).

50 A. Barlow, IEEE Elec. Insul. Magazine, 7(1), 8 (1991).

51 M.S. Khalil, IEEE Elec. Insul. Magazine, 13(6), 35 (1997).

52 K.S. Suh, C.R. Lee, Y. Zhu and J. Lim, IEEE Trans. Diel. Elec. Insul. 4, 681 (1997).

53 M.S. Khalil, A. Cherifi, A. Toureille and J-P. Reboul, IEEE Trans. Diel. Elec. Insul. 3, 743 (1996).

54 G. Chen, H.M. Banford and A.E. Davies, IEEE Trans. Diel. Elec. Insul. 5, 51 (1998).

55 M. Henriksen, J.T. Holb $\phi l l$ and R.J. Fleming, in Space Charge in Solid Dielectrics, ed. J.C. Fothergill and L.A. Dissado, The Dielectrics Society, 1998, p.235.

56 K.S. Suh, C.R. Lee, J.S. Noh, J. Tanaka and D.H. Damon, IEEE Trans. Diel. Elec. Insul. 1, 224 (1994).

57 A. Toureille and N. Vella, in Space Charge in Solid Dielectrics, ed. J.C. Fothergill and L. A. Dissado, The Dielectrics Society, 1998, p.59.

58 T.J. Lewis, IEEE Trans. Elec. Insul. EI-21, 289 (1986).

59 Y. Li and T. Takada, J. Phys. D: Appl. Phys. 25, 704716 (1992).

60 J.M. Alison and R.M. Hill, J. Phys. D: Appl. Phys. 27, 1291 (1994).

61 X. Wang, D. Tu, T. Muronaka, T. Takada, C. Shinoda and T. Hashizumi, IEEE Trans. Diel. Elec. Insul. 2, 467 (1995). 
62 F.N. Lim, R.J. Fleming and R.D. Naybour, Proc 3rd Inter. Conf. on Electric Charge in Solid Insulators, Tours, France, June-July 1998, ed. G.Damamme, Societe Francaise du Vide, pp. 329-338.

63 R.W. Greaves, E.P. Fowler, A. Goodings and D.R. Lamb, J. Materials Sci. 9, 1602 (1974).

64 B. Sanden, in Space Charge in Solid Dielectrics, ed. J.C. Fothergill and L.A. Dissado, The Dielectrics Soci- ety, 1998, p.225.

65 K.S. Suh, S.J. Hwang, J.S. Noh and T. Takada, IEEE Trans. Diel. Elec. Insul. 1, 1077 (1994).

66 D. Malec, R. Essolbi, H. The-Giam, Bui-Ai and B. Garros, IEEE Trans. Diel. Elec. Insul. 3, 64 (1996).

67 N. Hozumi, T. Takeda, H. Suzuki and T. Okamoto, IEEE Trans. Diel. Elec. Insul. 5, 82 (1998). 